\title{
Desempenho escolar em ciências: adequação de um sistema de avaliação para estudantes com transtornos da aprendizagem
}

Tiago Santos de Jesus tiagosantosdejesus2009@gmail.co

0000-0003-0183-4843

Universidade Federal de Sergipe, São Cristovão, Sergipe, Brasil.

Alice Alexandre Pagan apagan.ufs@gmail.com 0000-0002-9757-4304 Universidade Federal de Sergipe, São Cristóvão, Sergipe, Brasil.

Fábio Teotho Rocha fabio@enscer.com.br 0000-0003-3013-4117

Universidade Federal de Sergipe, São Cristóvão, Sergipe, Brasil.

\section{RESUMO}

O objetivo deste trabalho foi construir e adequar um instrumento de desempenho em larga escala de ciências para estudantes brasileiros com possíveis indicadores de transtornos funcionais específicos da aprendizagem. Foram coletados em quatro regiões do Brasil, em dois momentos: 19) foi aplicado um teste de desempenho abrangendo questões de Ciências, para 320 estudantes do 9o Ano e 10 Ano do Ensino Médio; em seguida, foram aplicados 117 questionários para mães/responsáveis dos estudantes que realizaram o teste de desempenho, sobre indicadores dos transtornos de aprendizagem desses alunos. Em se tratando do desempenho sobre os conteúdos de ciências referentes ao 9 ㅇ ano do ensino fundamental, houve uma frequência geral de acertos com índice de 30 a $70 \%$. Quando correlacionamos os fatores ambientais e biológicos com o desempenho de ciências os resultados não se mostraram significativos, revelando que as adequações do teste de desempenho propostas podem ser consideradas positivas para o processo inclusivo.
\end{abstract}

PALAVRAS-CHAVE: Avaliações externas. Transtornos da aprendizagem. Desempenho em ciências. 


\section{INTRODUÇÃO}

As habilidades cognitivas como: identificar, comparar e calcular, podem ser medidas pelo sistema de avaliação do desempenho escolar, proporcionando melhores intervenções do Estado em suas políticas públicas.

No ambiente escolar ocorre dois processos de avaliação: a avaliação interna, processo de compreensão da aprendizagem do estudante pelo professor, e a avaliação externa, que tem o intuito de avaliar o desempenho de grupos de estudantes de diferentes regiões do país (CAED, 2008).

Em se tratando da avaliação externa o mesmo ocorre em um processo homogêneo nos diferentes sistemas educacionais, utilizando como instrumento avaliativo testes de larga escala. Esses testes são compostos por itens de múltipla escolha e são considerados como testes padronizados, avaliando apenas um tipo de modalidade (KLEIN \& FONTANIVE, 1995; LOCATELLI, 2002; KATRINE, 2007).

Além disso, os programas de avaliação em larga escala podem possuir indicadores importantes, os quais fornecem informações a respeito das habilidades e competências das diferentes redes de educação (CAED, 2008).

Esses indicadores favorecem a interpretação de dados para gestores dos sistemas educacionais. A partir dos resultados obtidos, eles podem repensar o planejamento e as ações educativas que contribuem para planos mais eficientes e focados na melhoria do desempenho dos estudantes em suas instituições (ALMEIDA, 2014).

Os sistemas de avaliação têm a finalidade de abordar o sistema escolar como um grupo ou subgrupo de estudantes em diferentes anos através das avaliações em larga escala, sendo possível acompanhar a evolução do rendimento através dos índices mensurados (KLEIN \& FOTANIVE, 1995).

As avaliações externas segundo Belloni (1999) favorecem desenvolvimento do sistema de ensino, em termos de políticas públicas e de projetos destinados a diferentes instituições. Isso sendo fatores favoráveis para a melhora na gestão educacional no país.

Essa preocupação com o controle das políticas públicas educativas na qualidade do ensino ofertado contribuiu para que o Instituto Nacional de Estudos e Pesquisas Educacionais Anísio Teixeira (INEP) iniciasse as avaliações nacionais em larga escala através da aplicação de testes de desempenho (MENEZES, 2014).

Para avaliações em nível nacional do desempenho em ciências foram aplicados testes em larga escala nos anos de 1990, 1993, 1997, 1999 e 2001 pelo Sistema Nacional de Avaliação Básica (SAEB) promovidos pelo INEP. Os testes aplicados nos referidos anos tiveram como abordagem um modelo amostral direcionados à instituições privadas e públicas do país.

Segundo Almeida (2014) Menezes (2014) e Oliveira (2014) são poucas as avaliações externas que medem o desempenho em Ciências. Sendo que na matriz da aplicação de 1997, afirma uma das autoras, "fundamentaram-se em idéias de mensuração de habilidades, baseadas em competências em seus respectivos descritores" (ALMEIDA, 2014. p.51). De acordo com Brasil (2013) após reflexões sobre os itens que contemplavam essa matriz percebesse que os elementos ficavam limitados a determinados contextos, objetivos de conhecimento e operações cognitivas. 
Depois de doze anos sem aplicar teste em larga escala com questões voltadas ao Ensino de Ciências, o INEP volta a discutir no ano de 2013 as matrizes de referência do SAEB nos três componentes curriculares de ensino (Língua Portuguesa, Matemática e Ciências). Foi criada a matriz de Ciências além da revisão e atualização das demais que compõem o SAEB. Essa proposta apresentada e testada em 2013 assume a natureza de um estudo piloto a ser discutido posteriormente para o aperfeiçoamento com vistas a sua consolidação em 2015.

Segundo o Brasil (2013) a operação cognitiva solicitada ao respondente requer que ele resolva a situação-problema indicada pelo item, explicitando o que foi realizado em termos cognitivos, da ordem do pensamento, considerando o uso do conhecimento efetivado. Portanto, abrange o que fazer com o conhecimento e o tipo de uso cognitivo que se espera nos diferentes contextos da vida.

Para a construção dos descritores das matrizes de referência do SAEB de 1997 até 2001 cada habilidade busca manifestar uma operação cognitiva realizada com o uso de conteúdos de cada área de conhecimento. Segundo Brasil (2002) o conhecimento na perspectiva cognitivista leva o sujeito a compreender o significado do item para o sentido da informação exposta. $O$ indivíduo precisa passar pela ação de raciocinar, coordenar as informações em concordância com os itens propostos e eventualmente produzir novas informações significativas e fazer inferências quando necessário.

As construções intelectuais estabelecidas entre o sujeito-objeto do conhecimento podem receber denominações, dentre elas: habilidades e competências, processos, operações cognitivas ou habilidades. Essas ações desempenhadas pelo estudante da educação básica na matriz do SAEB para as Ciências da Natureza e Ciências Humanas são definidas em três categorias: 1) Reconhecimento de conceitos, ideias, fenômenos e/ou sistemas; 2) Compreensão de conceitos, ideias, fenômenos e/ou sistemas e 3) Aplicação de conceitos, ideias e/ou sistemas ou solução de problemas (BRASIL, 2013).

$\mathrm{Na}$ área de Ciências Naturais essas três categorias cognitivas estão organizadas na na matriz do SAEB 2013 em cinco eixos estruturantes, a saber: A) Terra e universo; B) Vida e ambientes; C) Ser humano e saúde; D) Materiais: constituição, propriedades e transformações e E) Energia: conservação e transformação.

O teste nacional de avaliação proposto pelo SAEB serviu de modelo base para que algumas unidades estaduais e municipais realizassem teste de desempenho. Segundo Horta Neto (2010) podemos citar: o Programa de Avaliação do Sistema Educacional do Pará (AVA), que aplicou o teste de desempenho entre 1996 e 2000, com estudantes do ensino fundamental; o Sistema de Avaliação Educacional de Pernambuco (SAEPE); o Sistema Mineiro de Avaliação da Educação Pública (SIMAVE); o Sistema de Avaliação do Rendimento do Rio Grande do Sul, o Sistema de Avaliação do Rendimento Escolar do Estado de São Paulo (SARESP) e a Prova São Paulo que avalia os estudantes da rede municipal nas disciplinas de ciências e Ciências naturais em anos alternados (ALMEIDA, 2014)

O SARESP realiza teste de desempenho em ciências desde 1997, tendo como finalidade de fornecer informações consistentes, periódicas e comparáveis sobre a situação das escolas básicas na rede pública de ensino paulista, com o intuito de orientar os gestores do ensino no monitoramento das políticas voltadas para a melhoria da qualidade do ensino no estado (BRASIL, 2012). 
O SARESP define que competências cognitivas são modalidades estruturais da inteligência, utilizadas pelo estudante para compreender ou resolver um problema. Para avaliação dessas competências o sistema de avaliação propõe três grupos: competências para observar; competência para realizar e competências para compreender somando ao todo trinta e seis habilidades para o nono ano do ensino fundamental (SÃO PAULO, 2009).

Além desses sistemas existentes no país, destaca-se uma avaliação internacional que tem como objetivo verificar o desempenho dos alunos nos países participantes. O PISA é desenvolvido e coordenado pela Organização para a Cooperação e Desenvolvimento Econômico (OCDE), no entanto, em cada país há uma coordenação nacional. No Brasil o INEP é responsável pelas aplicações (BRASIL, 2012).

O teste vem sendo aplicado desde o ano de 2000 a estudantes com idades de 15 anos, em triênios. A cada edição a prova enfatiza uma área de conhecimento. Os conteúdos de ciências foram aplicados no ano de 2006 e acontecerá uma nova aplicação em 2015 (MENEZES, 2014).

Dentre as habilidades cognitivas medidas na prova, o PISA prioriza três situações ou contextos: a) Pessoal, que centraliza o indivíduo entre familiares e grupos de colegas; b) Social, que abrange a interação com a comunidade e c) Global, em que os sujeitos são situados na vida através do mundo (BRASIL, 2012).

Os instrumentos utilizados nas avaliações destes testes vêm evoluindo com o tempo, além das aplicações tradicionais realizadas em cadernos de testes, e questionários socioeconômicos e culturais dos alunos e das escolas que participam do programa, o sistema em sua última aplicação adotou sistema online. (BRASIL, 2012).

\subsection{FATORES QUE PODEM IMPLICAR NO O DESEMPENHO DO ESTUDANTE}

Nos dias atuais os índices de desempenho dessas avaliações vêm ganhando discussões a respeito do sucesso e/ou fracasso nos resultados obtidos pelos estudantes. Segundo Lugli (2012), o fracasso pode ser esclarecido como condição discente de persistência a se manter em um baixo rendimento se comparado ao que esperam para a sua etapa de escolarização, com um histórico de múltiplas repetências acarretando no abandono escolar.

Vale à pena ressaltar que os fracassos escolares podem ser pertinentes a dois fatores: o primeiro relacionado ao processo de ensino e aprendizagem, onde muitas vezes a escola cobra mais do que se ensina (FERREIRO, 2010) e o segundo relacionado ao desenvolvimento do sujeito, formando uma rede que leva os aprendizes ao sucesso e/ou ao fracasso principalmente na leitura e na escrita (GOMES, 2006).

Outros fatores que podem interferir no desempenho são as condições sociais e clínicas dos estudantes e de seus familiares. Para auxiliar nessa visão os dados apresentados do Índice de Desenvolvimento Humano (IDH), têm como objetivo mensurar o desenvolvimento de uma nação em três pilares: saúde, que é medida pela expectativa de vida; educação, que avalia a permanência de alunos em diferentes faixas etárias e acesso ao conhecimento; e renda, que mede o padrão de vida dos indivíduos através da Renda Nacional Bruta (RNB) (BRASIL, 2010). 
Nessa visão, o IDH traz reflexões sobre a relação entre valores e problemas no campo da educação e segurança pública no Brasil, permitindo que gestores, sociedade e família reflitam sobre a importância das suas participações para qualidade de ensino no país.

O baixo desempenho escolar pode estar associado tanto a fatores biológicos relacionados à genética (TALLAL, 1991; RAMUS, 2006; SHAYWITZ E SHAYWITZ, 2005; GILBSON E GRUEN, 2008), quanto a condições ambientais da gestante, como desnutrição materna (GORDON, 1998; OKADO et al., 2001), depressão materna (GORDON, 1998), estresse durante a gestação (HAYASHI et al., 1998; OKADO et al. 2001), e uso de drogas pela gestante (SHAYWITZ \& SHAYWITZ, 2005; CONEWESSON, 2005).

Esses fatores biológicos agem como interferências nas Dificuldades de Aprendizagem (DA) que podem representar outras formas no desenvolvimento neurológico que impede a aprendizagem na leitura, na escrita e na resolução de problemas. Tal interferência no desenvolvimento das estruturas neurofisiológicas pode levar a algumas características clínicas de indivíduos que apresentam transtornos como a Dislexia, a Discalculia e o Transtorno do Déficit de Atenção e Hiperatividade (TDAH). A LDB, no. 9.364/96 passou a nominar esses tipos de alunos da educação especial como "educandos com deficiência, transtornos globais do desenvolvimento [...]" (BRASIL, 2013b, p.10).

Em conformidade com a Política Nacional de Educação Especial na Perspectiva da Educação Inclusiva (PNEE) de 2008, segundo Silva (2014) define-se que, o grupo de alunos atendido pela educação especial é aquele que apresenta Dislexia, Discalculia e TDAH dentre outros. Eles são considerados alunos com transtornos funcionais específicos.

Considerando a Constituição Federal de 1988 do nosso país, que determina que todos os cidadãos têm direito ao acesso à educação, é importante que se compreenda que a inclusão escolar se constrói na participação de crianças, jovens e adultos em todas as oportunidades sociais e educacionais oferecidas pelas instituições de ensino (MITTLER, 2003).

Nesse sentido, a educação inclusiva constitui um ensino voltado para todos principalmente com indivíduos que apresentam algum tipo de necessidades especiais ou transtornos funcionais específicos. Fazendo com que a educação inclusiva seja igualitária ao meio social desses estudantes (LIMA, 2006).

Pensando em inserir esses estudantes com transtornos em um sistema de avaliação em larga escala, adaptamos um teste na área de Ensino de Ciências. Para essa adaptação foi elaborado um questionário sobre indicadores a respeito dos transtornos da aprendizagem com o intuído de verificar se o teste formulado se apresenta de acordo com as especificidades desses estudantes.

\section{METODOLOGIA}

A aplicação dos 320 testes de desempenho ocorreu entre os meses de outubro e dezembro de dois mil e quatorze em quatro estados do Brasil dentre eles: duas escolas situadas em Mato Grosso - MT (39), uma escola no Rio Grande do Sul - RS (38), uma escola em São Paulo - SP (59) e duas escolas localizadas em Sergipe - SE (184). 
A escolha dessas escolas para a aplicação do teste de desempenho ocorreu da seguinte maneira: a) disponibilidade da aplicação da pesquisa na escola, b) presença em sua estrutura física de uma sala de computação com acesso à internet e c) existência de relação com algum pesquisador integrante da pesquisa em cada estado participante. Embora esses critérios estivessem mais ligados a questões logísticas do que a uma análise sobre índices de desempenho, não houve interferências nos resultados, posto que há estimativas da presença de crianças com dificuldades de aprendizagem devido a transtornos em todas as escolas brasileiras, bem como o estudo partiu de um comparativo dos resultados entre os alunos da amostra.

Para a aplicação do Teste com conteúdo do 9 Ano, escolhemos estudantes que se encontravam na rede de ensino estadual devidamente matriculados no $1^{\circ}$ Ano do Ensino Médio. Apenas em São Paulo a coleta foi feita no 9o Ano do ensino Fundamental devido a um lapso de comunicação com a equipe de coletores que lá atuou.

\subsection{QUESTIONÁRIO SOBRE INDICADORES DO TRANSTORNO DA APRENDIZAGEM}

Para avaliar se a adequação do teste foi significativa, foi elaborado um questionário com levantamento de indicadores que pudessem interferir no desenvolvimento neurofisiológico do educando. Como vimos, diversos estudos mostram os variados fatores biológicos e ambientais que podem alterar a neurofisiologia da criança e interferir no desempenho dos estudantes. Dentre eles: antecedentes familiares de transtornos de aprendizagem (possível fator genético), estresse e saúde materna durante a gravidez (GILBSON E GRUEN, 2008; GORDON, 1998; OKADO et al., 2001).

Foram aplicados 117 questionários as mães ou responsáveis dos mesmos estudantes que responderam ao teste de desempenho. Os responsáveis eram convidados voluntariamente para responder as perguntas elaboradas no questionário.

Esse convite era realizado nas seguintes maneiras: nas cidades de Aracaju - SE e Cuverlândia - MT, foram realizadas entrevistas durante as reuniões de pais proporcionadas pelas escolas. Nessa aplicação os pesquisadores liam o Termo de Consentimento Livre Esclarecido e explicavam o intuito da pesquisa. Em seguida eram feitas as perguntas seguindo o roteiro do questionário, ao final da aplicação foram lidas as respostas que os respondentes indicavam e os mesmos autorizavam o uso para análise.

Nas cidades de Cuiabá - MT, Santa Maria - RS e São Bernardo do Campo - SP o instrumento e o termo de Consentimento Livre Esclarecido eram entregues aos estudantes que os levaram para o preenchimento dos seus pais ou responsáveis.

\subsection{ANÁLISES DOS DADOS}

Para compreender e analisar os dados do teste de desempenho e do questionário sobre os indicadores dos transtornos, as informações foram processadas em um software estatístico em três modalidades de análise. A primeira utilizou a análise de frequências simples para o teste de desempenho, 
onde os dados foram organizados em três grupos de índices: Grupo 1 composto por questões nas quais os estudantes tiveram de $70 \%$ de acerto acima, Grupo 2 entre $60 \%$ e $69 \%$ de acertos e grupo 3 com índices abaixo de $60 \%$ de questões corretas.

Os indicadores do questionário foram processados também em frequências simples e organizados em três categorias que corresponderam aos subtópicos dos resultados: 1) Fatores fisiológicos do desenvolvimento, que tratam das memórias maternas e paternas sobre o desenvolvimento gestacional da criança bem como o possível uso de drogas durante a mesma; 2) Fatores psicológicos do desenvolvimento, relacionados a traumas psicológicos possivelmente sofridos pela mãe durante a gestação, bem como relacionados à criança após o nascimento e 3) Características hereditárias, se há diagnóstico de alguma doença associada à família da criança.

Outra análise estatística efetuada foi a regressão múltipla que buscava relacionar uma variável dependente em um conjunto de outras variáveis independentes.

Para análise dos índices das categorias do questionário, as perguntas foram agrupadas nos três fatores, gerando alguns índices: índice de uso de droga, índice fisiológico materno, índice fisiológico da saúde da criança, índice de estresse, índice hereditário além dos índices de acertos do teste. Esses dados foram apresentados no tópico seguinte.

\section{RESULTADOS}

Trezentos e vinte estudantes de redes estaduais de quadro regiões MT, RS, SP e SE responderam ao teste, dos quais $49 \%$ eram do sexo feminino e $51 \%$ do sexo masculino. Com idades predominantes de quinze anos $41,3 \%$, em seguida dezesseis anos $24,4 \%$ e quatorze anos $(20,9 \%)$.

A amostra correspondeu a $81,6 \%$ do 10 Ano do Ensino Médio e 18,4\% do 9o Ano do Ensino fundamental. Quanto ao formato de aplicação houve uma predominância no teste em computador (62\%).

As maiores populações consultadas foram de Sergipe $57 \%$ e São Paulo $18 \%$, respectivamente englobando $76 \%$ do total. Em seguida está Rio Grande do Sul com $11 \%$ e Mato Grosso $13 \%$, da amostra

Em se tratando do desempenho sobre os conteúdos de Ciências do nono ano do ensino fundamental, os resultados indicam uma distribuição bem próxima do normal, conforme observado no histograma (Figura 1). 
Figura 1 - Histograma demonstrando o desempenho dos relacionados aos conteúdos do nono ano da amostra geral.

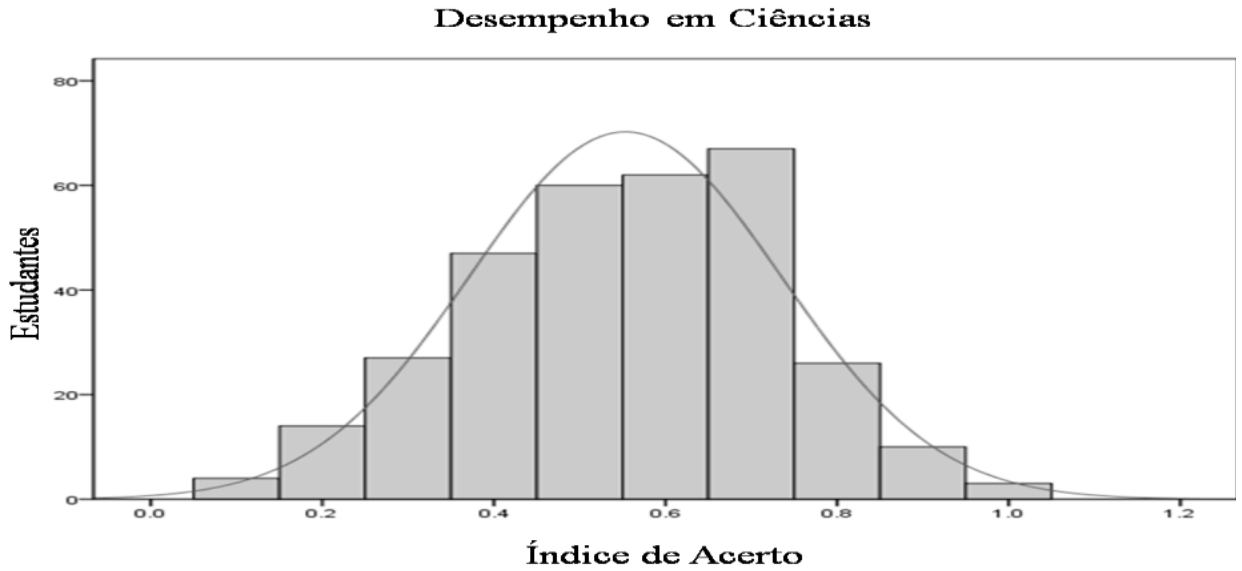

(Fonte: Arquivo do autor, 2015)

Na linha horizontal do histograma estão dispostos os números de acertos que variam entre 0.0 e 1.0, isso significa que quanto mais próximo de zero menor a quantidade de acertos na avaliação. Os valores do eixo vertical representam número de estudantes que acertaram aquela quantidade. A distribuição normal encontrada mostra que o teste apresentou o grau de complexidade adequado ao grupo.

As dez questões de ciências com conteúdos do 9o ano foram agrupadas de acordo com os índices de proporção de acerto e erro. Os descritores dessas questões foram expostos da seguinte maneira: Grupo 1 - questões com número de acertos igual ou superior a 70\%, Grupo 2 - entre 60\% e 69\% e Grupo 3 - abaixo de $60 \%$ (Tabela 1).

Tabela 1 - Proporção de acerto e erro para cada um dos descritores aplicados ao 9o ano no teste de desempenho em Ciências.

\begin{tabular}{c|l|c|}
\hline $\begin{array}{c}\text { ÍNDICE DE ACERTOS } \\
\text { DAS QUESTÕES DE } \\
\text { CIÊNCIAS }\end{array}$ & \multicolumn{1}{|c|}{ DESCRITOR } & $\begin{array}{c}\text { PROPORÇÃO DE } \\
\text { ACERTO (\%) }\end{array}$ \\
\hline $\begin{array}{c}\text { (IGUAL OU SUPERIOR A } \\
\text { 70\%) }\end{array}$ & $\begin{array}{l}\text { 7. Reconhecer maus hábitos } \\
\text { alimentares e suas } \\
\text { consequências }\end{array}$ & 88,1 \\
\hline \multirow{2}{*}{ (ENTRE 60\% E 69\%) } & $\begin{array}{l}\text { 3. Reconhecer o elemento } \\
\text { químico }\end{array}$ & 68,1 \\
\hline & $\begin{array}{l}\text { 4. Calcular o tempo de um } \\
\text { movimento uniforme }\end{array}$ & 65,6 \\
\cline { 2 - 3 } & $\begin{array}{l}\text { 2. Identificar alimentos que } \\
\text { possuem Vitamina C }\end{array}$ & 65,0 \\
\hline \multirow{2}{*}{ (ABAIXO DE 60\%) } & $\begin{array}{l}\text { 1. Identificar substância } \\
\text { compostas }\end{array}$ & $\begin{array}{l}\text { 9. Compreender o isolamento } \\
\text { térmico }\end{array}$ \\
\hline
\end{tabular}


celular

8. Compreender os efeitos da

diferença de pressão

6. Transformar escala Celsius

em Fahrenheit

10. Identificar elementos do

mesmo período da tabela

periódica

(Fonte: Arquivo do próprio autor, 2015)

As dez questões apresentadas no teste de desempenho estavam compostas da seguinte maneira: quatro eram sobre conteúdos de química, três itens relacionados à área de física e três descritores de ciências naturais.

Em se tratando da organização da estrutura das questões, a de número 7 da tabela 1, cujo descritor tinha por objetivo reconhecer maus hábitos alimentares e suas consequências, teve maior grau de acerto e segundo a consulta feita ao grupo que a elaboração ela foi tida como uma das mais fáceis do teste, considerando o nível de complexidade da série investigada. Segundo Haydt (2008) e Babbie (1999) os itens de um teste padrão devem ser compostos preferencialmente por questões medianas, ou seja, questões muitos fáceis ou muito difíceis de certa maneira não são capazes de caracterizar os vários níveis de desempenho do estudante.

As diferentes operações cognitivas avaliadas no teste estão centradas em habilidades de identificação e compreensão, os dois descritores relacionados a esta última tiveram menos de $60 \%$ de acertos, juntamente com outras três questões somando metade do teste de desempenho. Menezes (2014), ao analisar o teste piloto desta pesquisa, mostrou que em treze itens as habilidades de compreender tiveram porcentagem de acerto tanto nos maiores quanto nos menores escores mostrando que o descritor não parece ter sido um elemento importante para explicar o resultado.

Outro questionamento que Menezes (2014) faz é que no seu estudo piloto comparando às três séries nas quais foram aplicados o teste: segundo, quinto e nono; este último teve o pior resultado de desempenho.

Nesta pesquisa os estudantes tiveram seu desempenho entre 0.7 e 0.3 índices de acertos nas questões, também considerados baixos, se comparados com os relatórios de desempenho do PISA (2012) e São Paulo (2012). Apesar destes testes terem uma amostra bem maior que a deste trabalho, podemos dizer que os resultados do PISA corroboram com estes, já que em ambos os alunos tiveram desempenho menor do que o esperado.

Dentre os conteúdos avaliados podemos considerar que os alunos tiveram um desempenho melhor em conteúdo da área Biológica do que em Física e Química. Um ponto que chamou a atenção foi o baixo acerto nos itens de química ligado a conceitos sobre misturas simples e compostas. Menezes (2014) ressalta que esse problema se deve ao fato do estudante estar em contato com duas disciplinas novas em sua grade curricular, além de relacionar as mesmas com outras habilidades como calcular e manusear experimentos. Como esse teste foi aplicado principalmente para estudantes do 1 o ano do ensino médio os mesmos já 
deveriam ter aprimorado conceitos básicos de química como diferenciar substancias simples e compostas como também saber o conceito de pressão.

\subsection{RESULTADOS DOS QUESTIONÁRIOS}

Dos 320 estudantes do ensino fundamental e médio que responderam ao teste, 117 responsáveis pelos mesmos responderam ao questionário sobre fatores biológicos e ambientais relacionados aos transtornos de aprendizagem. Desses $50,4 \%$ eram correspondentes aos estudantes do sexo feminino e $49,6 \%$ do sexo masculino. De maneira geral os dados mostram um equilíbrio no número de estudantes entre os gêneros.

Desse universo de $100 \%$ da amostra composta por 117 responsáveis que disponibilizaram as informações, seja por entrevistas ou por formulários, as maiores populações foram de Sergipe (46\%) e Mato Grosso (25\%), respectivamente, englobando $71 \%$ do todo. Em seguida está Rio Grande do Sul $19 \%$ e São Paulo $10 \%$. Com relação à idade correspondente aos filhos dos responsáveis que preencheram ao questionário, houve uma predominância de quinze anos (50\%) e dezesseis anos (23\%).

Quando perguntados sobre qual vínculo familiar o respondente possuía com o estudante submetido ao teste de desempenho, $89,7 \%$ eram mães, $4,3 \%$ eram pais, $2,6 \%$ eram Tia ou Tio, 1,7\% eram madrasta, $1,8 \%$ se identificaram como avós do estudante.

Para análise de regressão múltipla que relacionou acertos dos discentes e os indicadores de transtorno de aprendizagem, foram agrupadas as perguntas do questionário em fatores, a saber: Índice de acerto das questões de Ciências (INDICEAC), Fisiológico Materno (INDFISMA), Fisiológico da Criança (INDFISCR), Psicológico da Criança (INDPSICR), Estresse (INDSTRESS), Droga (INDDROGA) e Hereditariedade (INDICE_H) (Quadro 1).

Quadro 1 - Descrição de cada índice analisado.

\begin{tabular}{|c|c|c|}
\hline CÓDIGO & ÍNDICE & \multicolumn{1}{|c|}{ INFORMAÇÕES AGRUPADAS NO ÍNDICE } \\
\hline & $\begin{array}{l}\text { As } 10 \text { questões de Ciências com os seguintes } \\
\text { descritores: Identificar substância compostas; } \\
\text { Identificar alimentos que possuem Vitamina C; } \\
\text { Reconhecer o elemento químico; Calcular o } \\
\text { tempo de um movimento uniforme; Classificar } \\
\text { os seres viventes de acordo com a nutrição } \\
\text { celular; Transformar escala Celsius em } \\
\text { Fahrenheit; Reconhecer maus hábitos } \\
\text { alimentares e suas consequências; } \\
\text { Compreender os efeitos da diferença de } \\
\text { pressão; Compreender o isolamento térmico e } \\
\text { Identificar elementos do mesmo período da } \\
\text { tabela periódica. }\end{array}$ \\
\hline INDICEAC & Acerto \\
\hline
\end{tabular}




\begin{tabular}{|c|c|c|}
\hline INDFISMA & $\begin{array}{l}\text { Fisiológico } \\
\text { Materno }\end{array}$ & $\begin{array}{l}\text { Durante a gestação: Teve problema de } \\
\text { sangramento? Teve problema de pressão } \\
\text { arterial? Diabetes? Problemas na placenta? } \\
\text { Problemas com a bolsa? Infecções? Teve } \\
\text { outros problemas de saúde? Sofreu } \\
\text { agressões? }\end{array}$ \\
\hline INDFISCR & $\begin{array}{l}\text { Fisiológico da } \\
\text { criança }\end{array}$ & $\begin{array}{l}\text { Enxerga bem? Ouve bem? Teve alguma } \\
\text { doença grave? Teve algum acidente craniano? } \\
\text { Houve algum problema durante o parto? } \\
\text { Nasceu normal ou roxa? }\end{array}$ \\
\hline INDPSICR & $\begin{array}{l}\text { Psicológico da } \\
\text { criança }\end{array}$ & $\begin{array}{l}\text { Sofreu alguma violência? Se relaciona bem } \\
\text { com os irmãos? Se relaciona bem com os } \\
\text { amigos? Tem sono agitado? Acorda } \\
\text { assustado? Gosta de estudar? Gosta da } \\
\text { escola? Tem dificuldade em alguma matéria? } \\
\text { Mudou muito de escola? }\end{array}$ \\
\hline INDSTRESS & Estresse & $\begin{array}{l}\text { Durante a gestação: Teve problema com o } \\
\text { marido/namorado? Teve problemas com a } \\
\text { família? Teve problemas com o emprego? } \\
\text { Teve problemas financeiros? Houve morte que } \\
\text { causou pesar/sofrimento? Sofreu algum } \\
\text { acidente? Sofreu agressões? }\end{array}$ \\
\hline INDDROGA & Droga & $\begin{array}{l}\text { Perguntas durante a gestação: Fumou? } \\
\text { Bebeu? Usou outro tipo de droga? }\end{array}$ \\
\hline INDICE_H & Hereditariedade & $\begin{array}{l}\text { Há parentes que apresentam: Epilepsia? } \\
\text { Alzheimer? Esquizofrenia? Depressão? } \\
\text { Deficiência mental? Dificuldade na } \\
\text { alfabetização? Dificuldade em Matemática? } \\
\text { Problemas de comportamento? }\end{array}$ \\
\hline
\end{tabular}

(Fonte: Arquivo do próprio autor, 2015)

Na análise de Regressão Múltipla foi utilizada uma variável dependente para cinco independentes. Segundo Kaszar \& Gonçalves (Sd) esse tipo de metodologia estatística permite que se estime o valor de uma variável com base num conjunto de outras.

De acordo com Levine et.al. (2008) uma vez o valor $p=000 \leq 0.05$ aceita-se a hipótese nula e podemos concluir que pelo menos uma das variáveis independentes do modelo está relacionada à dependente. Analisaremos os dados das significâncias que apresenta os dados individuais dos betas.

Ao verificamos a variação dependente dos índices de acertos (INDICEAC) com as cinco variáveis independentes verificamos que os valores de t (110) casos considerados, os resultados mostram que em nenhum caso o $\mathrm{p}$-level é igual ou menor que 0.05 (Tabela 2). Os resultados mostram que os indicadores dos transtornos não exerceram interferências significativas no desempenho dos estudantes (Tabela 2). 
Tabela 2 - Resultado da Regressão Múltipla entre índice de Acertos

Regressão Múltipla entre a variável do índice de acertos e os indicadores dos transtornos.

\begin{tabular}{|c|c|}
\hline \multicolumn{2}{|c|}{$R=0.12945453 R^{2}=0.01675848 R^{2}$ Ajustado $=-$} \\
\hline \multicolumn{2}{|c|}{$F(6.110)=0.31248 p<0.92931$ Padrão da Estimativa: 0.19538} \\
\hline \multicolumn{2}{|c|}{ Numero de Casos $=(117)$ Numero Considerado dos Casos (110) } \\
\hline \multicolumn{2}{|c|}{ Variável Dependente $=$ INDICEAC } \\
\hline Variáveis Independentes & p-level (Significância) \\
\hline INDDROGA & 0.258591 \\
\hline INDFISMA & 0.939315 \\
\hline INDSTRES & 0.638348 \\
\hline INDFISCR & 0.769056 \\
\hline INDPSICR & 0.955832 \\
\hline IND_H & 0.421646 \\
\hline
\end{tabular}

(Fonte: Arquivo do próprio autor, 2015)

Os dados apresentados na tabela 2 revelam que não houve uma relação entre os índices de acertos das questões com os indicadores dos transtornos ambientais e biológicos referente ao aprendizado do estudante. Esse resultado era esperado como hipótese de partida da pesquisa, posto que nossa preocupação era criar um teste que fosse adequado ao acesso de estudantes com dificuldades de aprendizagem. As questões produzidas seguiam um padrão que visava objetividade, imagens de suporte, pouco texto, além de suporte em áudio, nos casos dos testes aplicados em computador. Apesar de ser uma mostra pequena podemos afirmar que a adequação do teste atendeu as expectativas de contribuição para uma metodologia equitativa de avaliação.

\section{CONSIDERAÇÕES FINAIS}

Neste trabalho buscou-se construir e analisar um teste de desempenho em Ciências que pudesse ser adequado aos alunos com transtornos de aprendizagem, proporcionando aos mesmos, condições de igualdade com os demais alunos no processo de resposta às avaliações.

Nesse sentido aplicamos uma ferramenta para uma amostra brasileira de estudantes do nono ano do Ensino Fundamental e do primeiro ano do Ensino Médio. Não fizemos qualquer distinção entre os estudantes respondentes, no entanto, também aplicamos aos pais desses alunos, um questionário que nos pudesse apresentar possíveis indicadores de transtornos, para que pudessemos comparar respostas positivas a indicadores biológicos e ambientais de transtorno de aprendizagem e os resultados do desempenho em ciencias.

Os resultados mostraram que as adequações feitas na estrutura e nos conteúdos das questões se mostraram significativas de modo que quando comparamos as médias de acerto no questionário de desempenho com as respostas dos responsáveis sobre possíveis indicadores de transtornos, não 
obtivemos relação significativa. Isso leva a considerar que o teste realmente foi eficaz para dar oportunidades iguais aos alunos respondentes.

\section{AGRADECIMENTOS}

A Coordenação de Aperfeiçoamento de Nível Superior (CAPES), Observatório de Educação OBEDUC e ao Instituto Nacional Instituto Nacional de Estudos e Pesquisas Educacionais INEP pelo financiamento desse projeto de pesquisa e pelo fornecimento de bolsas de pesquisador e de mestrado aos seus autores. 


\title{
School performance in science: adequacy of an evaluation system for students with learning disorders
}

\begin{abstract}
The objective was to build and tailor a performance instrument large-scale science to Brazilian students with possible indicators of specific functional learning disorders. Were collected in four regions of Brazil, in two stages: 1) was applied a performance test covering science issues, to 320 students from Year 9 and 1 year of high school; then were applied 117 questionnaires to mothers / guardians of students who took the test performance on indicators of learning disorders such students. In terms of performance on the science content for the 9th grade of elementary school, there was a general frequency arrangements with $30-70 \%$ index. When we correlate the environmental and biological factors with the performance of science the results were not significant, showing that the adjustments of the proposed performance test may be considered positive for the inclusive process.
\end{abstract}

KEYWORDS: External evaluations. Learning disorders. Performance in science. 


\section{REFERÊNCIAS}

ALMEIDA, M. S. Análise de um processo de elaboração de um teste de desempenho em ciências. 2014. 98 p. Dissertação (mestrado em Ensino de Ciências e Matemática) - Universidade Federal de Sergipe, São Cristovão, 2014. Disponível em: <https://ri.ufs.br/handle/riufs/5069>. Acessado em: 20 de maio de 2014.

BABBIE, Earl. Métodos de pesquisas de survey. Ed. da UFMG, 1999.

BELLONI, I. Avaliação Institucional um instrumento de democratização da educação. Linhas Críticas, v. 5, no 9. jul. - dez. 1999. Dispónível em: $<$ http://periodicos.unb.br/index.php/linhascriticas/article/view/2752>. Acessado em: 20 de maio de 2014

BRASIL, INEP Inclusão de Ciências no Saeb: Documento Básico. Brasília-DF, Instituto Nacional de Estados e Pesquisa Educacional Anísio Teixeira, 2013a, p.36. Disponível em:

<http://download.inep.gov.br/educacao_basica/prova_brasil_saeb/menu_do_pr ofessor/matrizes_de_referencia/livreto_saeb_ciencias.pdf $>$. Acessado em: 20 de maio de 2014.

BRASIL. Instituto Nacional de Estudos e Pesquisas Educacionais (Inep). Saeb 2001: novas perspectivas. Brasília, 2002. 106 p. Disponível em:

$<$ http://portal.inep.gov.br/documents/186968/484421/Relat\%C3\%B3rio+SAEB+2 001+-+Matem\%C3\%A1tica/2abcece2-8582-4800-a263-

c37a5d3be9ae?version=1.0>. Acessado em: 20 de maio de 2014.

BRASIL, Relatório pedagógico 2010 SARESP Ciências da natureza (Biologia, Física e Química) [recursos eletrônicos] - 2012. Disponível em:

<http://saresp.fde.sp.gov.br/2010/Pdf/Relat/Relat\%C3\%B3rio_Pedag\%C3\%B3gic o_C\%C3\%AAncias_2010.pdf>. Acessado em: 20 de maio de 2014.

BRASIL: Relatório Nacional Pisa 2012: Resultados Brasileiros. 2010 [recursos eletrônicos] - Brasília, 2012. Disponível em:

<http://download.inep.gov.br/acoes_internacionais/pisa/resultados/2014/relato rio_nacional_pisa_2012_resultados_brasileiros.pdf $>$. Acessado em: 20 de maio de 2014.

BRASIL, LDB: Lei de Diretrizes e Bases da Educação Nacional: Lei no 9.394, de 20 de dezembro de 1996, que estabelece as diretrizes e bases da educação nacional [recurso eletrônico]. - 8. ed. - Brasília: Câmara dos Deputados, Edições Câmara, 2013b. 
CAED, U. F. J. F. Guia de Elaboração de Itens. Língua Portuguesa. Centro de Políticas Públicas e Avaliação da Educação da Universidade Federal de Juiz de Fora, 2008. Disponível em: <http://www.portalavaliacao.caedufjf.net/wpcontent/uploads/2012/02/Guia_De_-

Elabora\%C3\%A7\%C3\%A3o_De_Itens_LP.pdf>. Acessado em: 14 de maio de 2019.

CONE-WESSON, B. (2005) Prenatal alcohol and cocaine exposure: Influences on cognition, speech, language, and hearing. Journal of Communication Disorders, vol 38 (4), p. 279-302, 2005. Disponível em:

<https://www.ncbi.nlm.nih.gov/pubmed/15862811>. Acessado em: 15 de maio de 2019

FERREIRO, M. Reflexões sobre Alfabetização. São Paulo, Ed. 25. Cortez, 2010.

GIBSON, C. J; GRUEN, J. R.; The human lexinome: Genes of Language and reading. Jornal of Communication Disorders, vol 41 (5) p. 409-420, 2008. Disponível em: <https://www.ncbi.nlm.nih.gov/pubmed/18466916>. Acessado em: 15 de maio de 2019

GOMES, M. F. C. Dificuldades de aprendizagem na alfabetização. Belo Horizonte. Autêntica. 2. Ed. 3a reimpressão, 2006.

GORDON, N.; Some influences on cognition in early life: A Short review of recent opinions. European Journal of Paediatric Neurology, vol 2 (1), p. 1-5, 1998. Disponível em:

<https://www.sciencedirect.com/science/article/pii/1090379898800470>. Acessado em: 15 de maio de 2019.

HAYASHI, A.; NAGAOKA, M.; YAMADA, K.; ICHITANI, Y.; MIAKE, Y.; OKADO, N. Maternal stress induces synaptic loss and developmental disabilities of offspring. International Journal of Developmental Neuroscience, vol. 16 (3-4), p. 209-216, 1998. Disponível em:

<https://www.ncbi.nlm.nih.gov/pubmed/9785117>. Acessado em: 15 de maio de 2019

HAYDT, R. C. C. Avaliação do processo ensino-aprendizagem. 6. ed. São Paulo: Ática, 2008.

KATRINE, G. Teoria de resposta ao Item na avaliação de qualidade de vida idosos. Dissertação (Mestrado em Epidemiologia). Universidade do Rio Grande do Sul, Porto Alegre, 2007. 
KLEIN, R.; FONTANIVE, N. S. Avaliação em larga escala: uma proposta inovadora. Em Aberto, Brasília, ano 15, n.66, abr./jun. 1995. Disponível em: <http://emaberto.inep.gov.br/index.php/emaberto/article/view/2025>. Acessado em: 15 de maio de 2019

LEAL, D. MAKELINY, G. Dificuldades de Aprendizagem: um olhar psicopedagógico. Curitiba: X IBPEX, 2011.

LEVINE, D. M.; STEPHAN, D; KREHBIEL, T. C; BERENSON, M. L. Estatística: teoria e aplicações. 5. ed. Rio de Janeiro: LTC, 2008 XXV, 752 p

LOCATELLI, I. Construção de instrumentos para a avaliação de larga escala e indicadores de rendimento: o modelo Saeb. Estudos em Avaliação Educacional, São Paulo, n. 25, jan./jun. 2002. Disponível em:

<http://publicacoes.fcc.org.br/ojs/index.php/eae/article/view/2189>. Acessado em: 15 de maio de 2019

MENEZES, M. O. Relações entre comportamento social e desempenho escolar em ciências: um estudo com alguns alunos de escolas brasileiras. 2014. 121 p. Dissertação (mestrado em Ensino de Ciências e Matemática) - Universidade Federal de Sergipe, São Cristovão, 2014.

OKADO, N.; NARITA, M.; NARITA, N. A biogenic amine-synapse mechanism for mental retardation and developmental disabilities. Brain and Development, vol 23, p. S11-S15, 2001. Disponível em:

<https://www.ncbi.nlm.nih.gov/pubmed/11738835>. Acessado em: 15 de maio de 2019.

OLIVEIRA, G. V. A. Relações entre o desempenho escolar em leitura e a aprendizagem de ciências: um estudo com alunos do ensino fundamental. 2014. 144 p. Dissertação (mestrado em Ensino de Ciências e Matemática) Universidade Federal de Sergipe, São Cristovão, 2014. Disponível em: <https://ri.ufs.br/handle/riufs/5164>. Acessado em: 20/05/2014.

RAMUS, F. Genes, brain, and cognition: A roadmap for the cognitive scientist. Cognition, vol. 101, n. 2, p. 247-269, 2006. Disponível em: <https://www.ncbi.nlm.nih.gov/pubmed/16725134>. Acessado em: 15 de maio de 2019.

SÃO PAULO, Matriz de referência para a avaliação Saresp: documento básico/Secretaria da Educação; coordenação geral, Maria Inês Fini. - São Paulo: SEE, 2009. 174 p. v.1. 
SHAYWITZ, S. E. and SHAYWITZ, B. A. Dyslexia (Specific Reading Disability). Biological Psychiatry (2005) vol. 57, n.11, p. 1301-1309, 2005. Disponível em: <https://www.ncbi.nlm.nih.gov/pubmed/15950002>. Acessado em: 15 de maio de 2019

SILVA, L. G. S. Educação inclusiva: práticas pedagógicas para uma educação sem exclusão. São Paulo, SP: Paulinas, 2014.

TALLAL, P. Hormonal influences in developmental learning disabilities. Psychoneuroendocrinology, vol. 18, p. 203 - 211, 1991. Disponível em: <https://www.sciencedirect.com/science/article/pii/0306453091900799>. Acessado em: 15 de maio de 2019.

Recebido: 2015-04-05

Aprovado: 2019-05-14

DOI: $10.3895 /$ rbect.v12n2.2864

Como citar: JESUS, T. S.; PAGAN, A. A.; ROCHA, F. T. Desempenho escolar em ciências: adequação de um sistema de avaliação para estudantes com transtornos da aprendizagem. Revista Brasileira de Ensino de Ciência e Tecnologia, v. 12, n. 2, 2019. Disponível em: <https://periodicos.utfpr.edu.br/rbect/article/view/2864>. Acesso em: xxx.

Correspondência: Tiago Santos de Jesus - tiagosantosdejesus2009@gmail.com Direito autoral: Este artigo está licenciado sob os termos da Licença Creative Commons-Atribuição 4.0 Internacional.

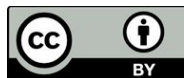

